\title{
Visual artist price heterogeneity
}

\author{
Massimiliano Castellani ${ }^{1 *} \cdot$ Pierpaolo Pattitoni $^{2} \cdot$ Antonello Eugenio Scorcu $^{1}$ \\ ${ }^{1}$ Department of Economics, University of Bologna, Bologna, Italy \\ ${ }^{2}$ Department of Management, University of Bologna, Bologna, Italy
}

Received: 22 June 2012

Revised: 27 September 2012

Accepted: 24 October 2012

\begin{abstract}
This paper proposes an empirical analysis to establish the determinants of Artist Price Heterogeneity (APH), using a unique dataset, which comprises all artwork sales occurred in Italy between 2006 and 2010. APH is measured by Gini indices calculated on artist price distributions. A Beta Regression Model (BRM) is estimated to account for the characteristic of the dependent variable, which can only assume values in the standard unit interval. Our analysis shows that APH is influenced by number of trades, average price, artist specialization, descent, fame, production, market structure and nationality, and artistic period.
\end{abstract}

Keywords: cultural economics, beta regression model, price heterogeneity

JEL Classification Codes: Z11, C25

\section{Introduction}

Over the period 1997-2012, Pablo Picasso was traded 35,743 times in the major international art auctions, with a price range of about 76,000,000 Euros. Over the period 1992-2012, Damien Hirst was traded 2,753 times, with a price range of about 17,000,000 Euros. These examples illustrate the high degree of APH that may characterize artist price distributions.

*Corresponding author. E-mail: m.castellani@unibo.it.

Citation: Castellani, M., P. Pattitoni and A.E. Scorcu (2012) Visual artist price heterogeneity, Economics and Business Letters, 1(3), 16-22. 
There are several possible explanations for heterogeneity. If artists are similar to monopolistic firms, APH may be driven by demand or supply factors. Demand factors comprise heterogeneity in buyers' willingness to pay, preferences, and income. Supply factors include product diversification, quality differentiation, and price discrimination strategies as well as artist technology (e.g., talent, education, and techniques). All these factors are not easily observable or measurable.

Given the demand factors (and other contextual factors), APH is higher for artists who adopt (or may adopt) product diversification, quality differentiation and price discrimination strategies. Thus, a high degree of heterogeneity is generally observed for artists with high market power. Picasso, the artist with the highest degree of APH, has, in fact, adopted diversification strategies by producing several art forms (e.g., paintings, drawings, and prints), differentiation strategies by producing artworks of different quality and variety, and price discrimination strategies by producing multiple artworks with different prices. To exploit his market power, Damien Hirst has opened a shop for his artworks.

Analyzing APH is interesting for both artists and dealers (auction houses and galleries). Artists operate on the primary market and control supply factors. Dealers operate mainly on the secondary market, and form their artist portfolios trying to exploit APH to maximize their profit, but do not have direct control over supply factors. However, several observable characteristics, that influence APH, may be used as proxies for these unobservable factors and may guide dealers in forming their portfolios. ${ }^{1}$ In this paper, we identify some of these observable characteristics.

Using a unique hand collected dataset, which comprises all artwork sales occurred in Italy between 2006 and 2010, we calculate an APH index for all artists in our dataset. Then, using observable characteristics as proxies for unobservable supply factors and a novel econometric approach (BRM), we identify the main determinants of APH.

\section{Data}

We base our empirical analysis on a unique dataset we collected from the Artist Re-sale Rights (ARR) archives of the Italian public performance-rights organization (SIAE). Our sample consists of 22,921 sales involving professional intermediaries that occurred in Italy between 2006 and 2010. For each artist, we computed a measure of APH and collected a number of variables from several sources. The total number of artists is 1180 .

Our dataset is characterized by some important features. We consider only artworks with a minimum sale price of 3,000 Euros, as the ARR applies only this price class. ${ }^{2}$ All artworks considered are produced by artists who died less than 70 years ago, which is the range of application of the ARR. All recorded sales are mediated by professional dealers (reducing the possibility of fakes). ${ }^{3}$ This point deserves some considerations. Since we do not observe the first offer price of artist artworks, we cannot measure the actual artist price distribution heterogeneity. All that we can observe are secondary market prices. However, since dealers try to exploit artist market power to maximize their profits, we assume that secondary market price distribution conforms to primary market price distribution.

After having presented the main features of our dataset and the potential limitations of our empirical analysis, we describe the variables at our disposal. Descriptive statistics are provided in Table 1 and Figure 1.

\footnotetext{
${ }^{1}$ Candela et al. (2012) explain Tribal artwork marketability using observable signs and signals as a proxy of unobservable quality factors.

${ }^{2}$ Artworks that sale at a price lower than 3000 Euros are typically drawings, photographs and graphics. Even excluding these artworks from the analysis, our results remain valid for the most important art forms (such as painting and sculpture).

${ }^{3}$ For a study on the impact of fakes on the art market see Bocart and Oosterlinck (2011).
} 
Figure 1. Histogram of APH with kernel density estimate

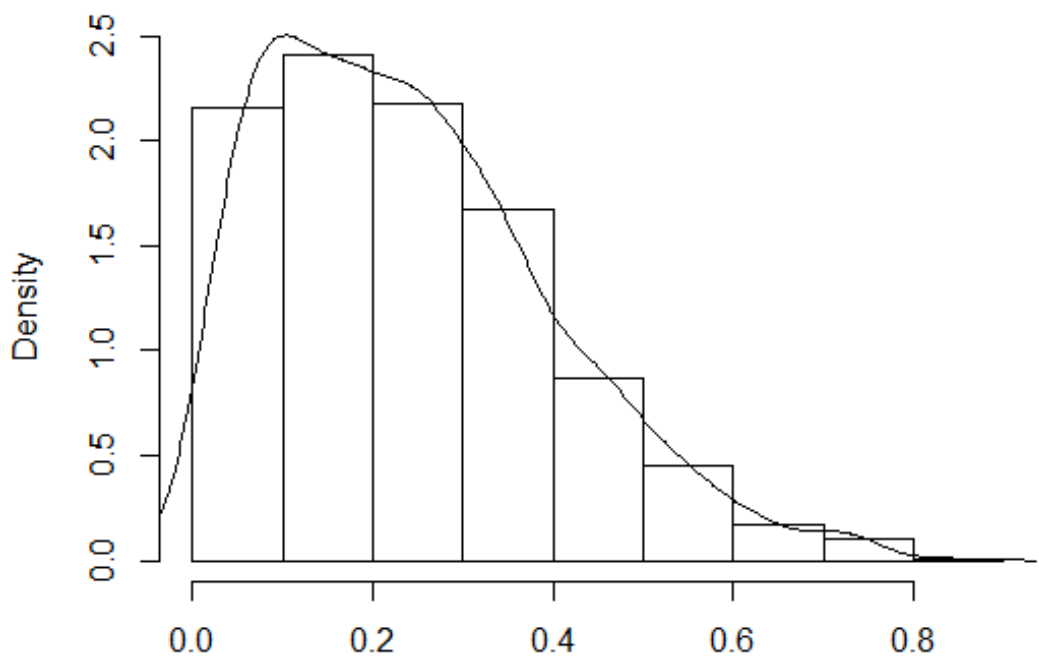

Price Heterogeneity

Table 1. Descriptive statistics

\begin{tabular}{|c|c|c|c|c|c|c|c|}
\hline Variable description & No & Yes & & & & & \\
\hline \multirow[t]{2}{*}{$\mathrm{W}$} & 881 & 299 & & & & & \\
\hline & [74.66] & [25.34] & & & & & \\
\hline \multirow[t]{2}{*}{ MF } & 408 & 772 & & & & & \\
\hline & [34.58] & [65.42] & & & & & \\
\hline \multirow[t]{2}{*}{$\mathrm{T}$} & 630 & 550 & & & & & \\
\hline & [53.39] & [46.61] & & & & & \\
\hline \multirow[t]{3}{*}{$\mathrm{AD}$} & 1117 & 63 & & & & & \\
\hline & [94.66] & {$[5.34]$} & & & & & \\
\hline & $1850-1875$ & $1875-1900$ & $1900-1925$ & $1925-1950$ & $1950-1975$ & $1975-2000$ & \\
\hline \multirow[t]{3}{*}{$\mathrm{P}$} & 61 & 246 & 268 & 202 & 219 & 184 & \\
\hline & [5.17] & [20.85] & [22.71] & [17.12] & [18.56] & [15.59] & \\
\hline & Min. & 1st Qu. & Median & Mean & 3rd Qu. & Max. & Std. Dev. \\
\hline $\mathrm{APH}$ & 0.00 & 0.12 & 0.22 & 0.24 & 0.34 & 0.85 & 0.16 \\
\hline G & 0.00 & 0.25 & 0.50 & 0.53 & 0.88 & 1.00 & 0.35 \\
\hline $\mathrm{E}$ & 27.00 & 66.00 & 87.00 & 90.12 & 115.00 & 185.00 & 31.35 \\
\hline NT & 2 & 3 & 6 & 19.42 & 16 & 418 & 40.48 \\
\hline AP & 3,150 & 5,150 & 7,823 & 15,600 & 14,750 & 376,100 & $26,471.42$ \\
\hline
\end{tabular}

Percentage in parentheses 
APH is the dependent variable in our regression analysis. For each artist, we compute the Gini index of her price distribution. The Gini index is a concentration coefficient that ranges from 0 to 1: when the price distribution is heterogeneous, the Gini coefficient is equal to 1; when the price distribution is homogenous, the Gini coefficient is equal to zero. It is evident from Figure 1 and Table 1 that APH is asymmetrically distributed among artists: the vast majority of artists exhibit a relatively low level of this variable, whereas artists with a high Gini index are not frequent. Thus, few and famous artists (e.g., Pablo Picasso and Damien Hirst) are located on the right tail and exhibit a high degree of heterogeneity.

NT is the number of trades for a given artist. Assuming that a different artwork is exchanged in each transaction - a reasonable hypothesis given that the probability of re-sale of the same artwork over a period of 5 years is low - this variable may be considered as a proxy for the artist production variety (for more details on re-sale frequencies see Ginsburgh et al., 2006).

AP is the logarithmic average price of trades per artist. This variable may be considered as a proxy of artwork quality.

MF is a dummy variable equal to 1 if the artist does not specialize in only one form of art (such as painting or sculpture), but on different art forms.

$\mathrm{AD}$ is a dummy variable equal to 1 if the artist is of artist descendant and 0 otherwise. It is questionable if this variable may be considered as a proxy for inherited artist talent or it simply influences APH as an effect of parents' fame.

$\mathrm{T}$ is a dummy variable equal to 1 if the artist is a member of SIAE. It is important to note that only artists traced by SIAE receive the re-sale royalties. For this reason, traced can be considered as a proxy for the fame of an artist. In fact, the most famous artists are generally the most traded on the market. ${ }^{4}$

$\mathrm{E}$ is the difference between year 2010 and the artist year of birth. Therefore, this variable is related to the number of years from which an artist is on the market. A longer existence is often associated with a larger artistic production.

$\mathrm{G}$ is the number of trades intermediated by art galleries over the total number of trades. This variable is important since art galleries and auction houses have a different selection procedure of artists and artworks as well as different degree of price flexibility.

$\mathrm{W}$ is a dummy variable equal to 1 if the artist is not Italian. It is worth noting that not all artworks traded are from Italian artists even if our dataset only refers to trades that took place in Italy.

$\mathrm{P}$ is a set of six dummies indicating the artistic period of the artist. To assign an artist to an artistic period, we consider the historical period in which the artistic movement to which she belongs has developed. Our dataset includes only modern and contemporary artists.

\section{Methods}

Let $y_{i}$ denote APH for artist $i$ and $\mathbf{x}_{i}$ a $k \times 1$ vector that includes all the explanatory variables described in section 2. Two critical aspects must be considered when modeling a concentration index: (1) the choice of an adequate functional form for the model and (2) the assumption on the distribution of the response variable.

APH is a variable that can only assume values in the standard unit interval. We are interested in explaining the expected value of $y_{i}$ given $\mathbf{x}_{i}, \mu_{\mathrm{i}} \equiv \mathrm{E}\left(y_{i} \mid \mathbf{x}_{i}\right)$. However, the characteristics of our response variable force us to depart from OLS. Since we must be sure that $\mu_{i} \in(0,1)$ for every $\mathbf{x}_{i}$, the

\footnotetext{
${ }^{4}$ Since the royalties of the re-sale right are proportional to the number of trades, the most famous artists are also those who have the greatest interest to be traced by SIAE.
} 
OLS estimator of $\boldsymbol{\beta}$ in the linear model is not a suitable candidate, as it can predict values outside the standard unit interval. We can then use a functional form such that $\mathrm{g}\left(\mu_{i}\right)=\mathbf{x}_{i}^{T} \boldsymbol{\beta}$, for a given choice of the link function, $\mathrm{g}(\cdot)$. A common choice for $\mathrm{g}(\cdot)$ is the Logit transformation, $\mathrm{g}\left(\mu_{i}\right)=\ln \left(\mu_{\mathrm{i}} /\left(1-\mu_{\mathrm{i}}\right)\right)$.

Furthermore, variable defined in the standard unit interval are typically asymmetric and heteroscedastic. With this kind of variables, assuming that the response variable $y_{i}$ follows a beta distribution, $y_{i} \mid \mathbf{x}_{i} \sim \mathrm{B}\left(\mu_{\mathrm{i}}, \phi\right)$, is convenient. In the previous expression, $\phi \in \mathfrak{R}^{+}$is a precision parameter that effect the variance of $y_{i}, \operatorname{Var}\left(y_{\mathrm{i}}\right)=\mu_{\mathrm{i}}\left(1-\mu_{\mathrm{i}}\right) /(1+\phi)$. Thus, this regression model is naturally heteroscedastic (the variance of the response variable varies with its mean) and easily accommodates asymmetries (given the flexibility of the beta distribution).

Given a random sample $y_{1}, \ldots, y_{n}$, the $\mathrm{BRM}$ is thus defined as $y_{i} \mid \mathbf{x}_{i} \sim \mathrm{B}\left(\mu_{\mathrm{i}}, \phi\right)$, $\ln \left(\mu_{\mathrm{i}} /\left(1-\mu_{\mathrm{i}}\right)\right)=\mathbf{x}_{i}^{T} \boldsymbol{\beta}$ (Cribari-Neto and Zeileis, 2010; Ferrari and Cribari-Neto, 2004). Parameter estimation in the BRM is obtained through the maximum likelihood method.

\section{Results}

Looking at the results in Table 2, we see that all variables are significant in explaining APH. This result is confirmed by a LR test that strongly rejects the hypothesis that all coefficients in the model except the intercept are equal to zero $\left(\chi^{2}(13)=867.91\right.$, p-value $\left.=0.000\right)$.

$\mathrm{NT}, \mathrm{AP}, \mathrm{MF}, \mathrm{AD}, \mathrm{T}$, and $\mathrm{E}$ have a positive coefficient; $\mathrm{G}$ and $\mathrm{W}$ have a negative coefficient. A joint Wald test on all the six artistic period dummies $\left(\chi^{2}(5)=14.00\right.$, p-value $\left.=0.016\right)$ shows a significant artistic period effect on APH.

NT and AP have a positive coefficient, indicating that greater artistic production variety and artwork quality are associated with higher APH.

MF has a positive coefficient, showing that the higher is the degree of diversification in an artist production, the greater is her APH.

The coefficient of AD is positive. This coefficient suggests that artists of artist descendant exhibit higher APH. This may be a consequence either of inherited artistic talent or parents' fame.

Since $\mathrm{T}$ is related to an artist degree of fame, it positively affects the artist market power and, thus, her APH.

E has a positive coefficient, evidencing that longer existence, and thus larger artistic production, is associated with greater APH.

Since galleries follow fixed price strategies, we find a negative sign for the coefficient associated with G.

The coefficient of $\mathrm{W}$ is negative. This negative coefficient can be explained by a form of home bias similar to that observed on financial markets: the power of Italian artists on the Italian market is greater than the power of foreign artists. This greater power positively affects APH. It is worth noting that if only the more expensive artworks from non-Italian artists get into Italy, the price heterogeneity measure of non-Italian artists may be biased. Caution is needed in interpreting this result.

A concern with our analysis is that the effect of NT and AP on APH may be nonlinear. To test the non-linearity hypothesis, we consider a semiparametric extension of our BRM, in which the response variable is an unknown function of NT and AP. We use regression splines to estimate this function from the data (Hastie et al., 2009). Two Wald-test statistics (one for the number of trades and one for the average price) reject the null hypothesis of linear effects of these variables $\left(\chi^{2}(5)=506.9\right.$, p-value 
$=0.000 ; \chi^{2}(5)=927.55, \mathrm{p}$-value $\left.=0.000\right)$. Since the coefficients on all the other variables in this augmented model are roughly the same as those of the basic BRM, we can rule out that non-linearity invalidates our inferences.

Table 2. Beta Regression Model

Mean model

\begin{tabular}{|c|c|c|c|}
\hline Variable description & Estimate & Std. Error & Sign. \\
\hline Intercept & -7.5033 & 0.2305 & $* * *$ \\
\hline NT & 0.0043 & 0.0004 & $* * *$ \\
\hline AP & 0.6290 & 0.0240 & $* * *$ \\
\hline MF & 0.1011 & 0.0390 & $* * *$ \\
\hline $\mathrm{AD}$ & 0.1656 & 0.0777 & $* *$ \\
\hline $\mathrm{T}$ & 0.1759 & 0.0408 & $* * *$ \\
\hline $\mathrm{E}$ & 0.0041 & 0.0008 & $* * *$ \\
\hline G & -0.2794 & 0.0562 & $* * *$ \\
\hline $\mathrm{W}$ & -0.1545 & 0.0461 & $* * *$ \\
\hline P (Chi-squared) & 14.00 & & $* *$ \\
\hline \multicolumn{4}{|c|}{ Precision model } \\
\hline Variable description & Estimate & Std. Error & Sign. \\
\hline phi & 13.3854 & 0.5428 & $* * *$ \\
\hline
\end{tabular}

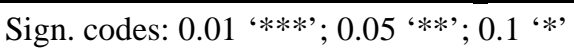

\section{Conclusions}

This paper proposes an empirical analysis to establish the determinants of APH. Using a unique dataset and a novel econometric approach, we show that APH is explained by several observable characteristics.

This analysis is valuable for both artists and dealers. Artists and dealers exploit APH to maximize their profit. While artists have direct control on unobservable supply factors, dealers can only observe characteristics that influence APH. These characteristics may be used as proxies for these unobservable factors and may guide dealers in forming their portfolios. In this paper, we identify some of these observable characteristics. Our analysis shows that APH is positively influenced by NT, AP, MF, AD, T, and $\mathrm{E}$, and negatively affected by $\mathrm{G}$ and W. Furthermore, we observe a significant artistic period effect on APH.

Acknowledgements. We are grateful to Guido Candela. We are indebted to an anonymous referee for his/her valuable comments. The usual disclaimers apply. 


\section{References}

Bocart, F. and Oosterlinck, K. (2011) Discoveries of fakes: their impact on the art market, Economics Letters, 113, 124-126.

Candela, G., Castellani, M. and Pattitoni, P. (2012) Tribal art market: signs and signals, Journal of Cultural Economics (forthcoming).

Ferrari, S. and Cribari-Neto, F. (2004) Beta regression for modelling rates and proportions, Journal of Applied Statistics, 31, 799-815.

Ginsburgh, V., Mei, J. and Moses, M. (2006) The computation of prices indices, in Handbook of the Economics of Art and Culture, Elsevier, 947-979.

Hastie, T., Tibshirani, R. and Friedman, J. (2009) The elements of statistical learning: data mining, inference and prediction, Springer-Verlag, New York.

Zeileis, A. and Cribari-Neto, F. (2010) Beta regression in R, Journal of Statistical Software, 34, 1-24. 